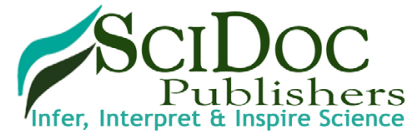

International Journal of HIV/AIDS and Research (IJHR)

ISSN 2379-1586

\title{
CD4+ Cell Count, Lipid And Lipoprotein Levels In Hiv Patients On Drug Treatment
}

Research Article

Adedokun Kamoru A ${ }^{1,5^{*}}$, Olisekodiaka Japhet $\mathrm{M}^{1,4}$, Adeyeye Adetunji $\mathrm{D}^{2}$, Adepeju Akinlawon $\mathrm{A}^{2}$, Muhibi Musa A ${ }^{3}$, Onifade Abdufatah A $\mathrm{A}^{5}$, Olaoye Jelili $\mathrm{A}^{6}$, Adetoro Taofik A ${ }^{1}$, UGWU Prince $\mathrm{I}^{1,5}$, Oyenike Musiliu A ${ }^{1}$

${ }^{1}$ Department of Biomedical Science, Ladoke Akintola University of Technology, Osogbo. Osun State, Nigeria.

${ }^{2}$ Department of Chemical Pathology, Ladoke Akintola University of Technology Teaching Hospital, Osogbo, Osun State, Nigeria.

${ }^{3}$ Department of Haematology, Ladoke Akintola University of Technology Teaching Hospital, Osogbo, Osun State, Nigeria.

${ }^{4}$ Department of Chemical Pathology, Faculty of Medicine, Nnamdi Azikwe University, Awka, Anambra State, Nigeria.

${ }^{5}$ Department of Chemical Pathology, University of Ibadan, Ibadan, Oyo State, Nigeria.

${ }^{6}$ Department of Chemistry, Ladoke Akintola University of Technology, Ogbomosho, Oyo State, Nigeria.

\section{Abstract}

Background: Previous reports showed lack of consensus on the possible etiology of coronary artery disease (CAD) between HIV-treatment with highly active antiretroviral therapy (HAART) and HIV-infection in particular. The aim of this study was to find out correlations of HIV-treatment and HIV-infection with CAD risk.

Method: One hundred and twenty (120) participants involving HIV-patients on treatment $(\mathrm{n}=40)$, treatment-naïve $(\mathrm{n}=$ 40) and equal number of age- and sex-matched controls were enrolled. The total cholesterol, triglycerides and lipoprotein (HDL-C) were analyzed using spectrophotometry. The LDL-C was calculated using Friedewald equation, TC/HDL-C and LDL-C/HDL-C ratios were also calculated. The CD4+ cell count was determined using flow cytometry.

Result: The mean plasma total cholesterol levels in patients' groups on treatment and treatment-naïve were significantly reduced when compared with controls, but the mean triglyceride levels for both treatment and the treatment-naïve groups were significantly increased when compared with controls. However, HDL-C and LDL-C values for patients on HAART and the treatment-naive were significantly reduced when compared with controls respectively. The CAD risk predictors, LDL-c and TC/HDL-C ratio, were significantly increased in patients on HAART when compared with the treatment-naive. The mean CD4+ cell count in treatment-naive was significantly lowered against both groups for treatment and controls. Conclusion: In this present study, abnormal lipid profile was associated with both HIV-infection and HAART-treatment. However, TC/HDL-C ratio, the strong predictor of CAD events in metabolic disorder was markedly high in HAARTtreatment and the associated difference may threaten higher risk for cardiovascular disease (CVD) during treatment.

Keywords: Coronary Artery Disease; Dyslipidemia; Highly Active Antiretroviral Therapy; Human Immunodeficiency Virus.

\section{Introduction}

Human immunodeficiency virus (HIV) as the etiological agent of acquired immunodeficiency syndrome (AIDS) causes progressive impairment of the body's cellular immune system thus resulting in increased susceptibility to infections [11, 24]. Currently, two immunological types are known, HIV-1 and HIV-2. HIV-1 is an enveloped RNA retrovirus which causes most HIV infections worldwide and HIV-2 which is found mainly in West Africa [6].
HIV is transmitted by direct inoculation into the bloodstream; otherwise, after contact and attachment through mucosal surfaces it preferentially infects CD4+ cells. However, HIV also attaches other co-receptors such as CCR5 and CXCR4 lying on the cell surface and infect that cell. Within the cell, viral RNA is transcribed to DNA by the HIV reverse transcriptase. Also, the HIV protease enzyme cleaves the viral polyprotein to form mature viral particles, which are then released from cells to infect other

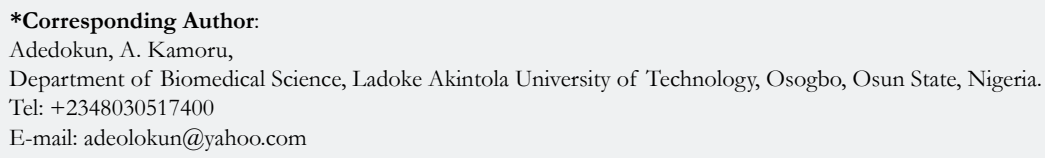

Copyright: Adedokun Kamoru A ${ }^{\circ}$ 2017. This is an open-access article distributed under the terms of the Creative Commons Attribution License, which permits unrestricted use, distribution and reproduction in any medium, provided the original author and source are credited. 
cells [25]. HIV/AIDS incident was formally discovered in Nigeria in 1986 and since then the prevalence rate has been increasing in the country. It increased from $1.6 \%$ to $5.8 \%$ in the period between 1991 to 2001. The estimated number of affected person in 2006 was 2.99 million with female constituting about 58\% [26].

Some studies $[23,46,47]$ indicated that Nigeria has the third highest number of people estimated to be living with HIV/ AIDS in the world (3.6 million as of the end of 2003), after South Africa and India. HIV prevalence is high among young people in Nigeria, especially young women [46-48]. Among those ages 15-24, the estimated number of young women living with HIV/ AIDS was almost twice that of young men in the country [46, 47]. In 2003, 290,000 children in Nigeria were estimated to be living with HIV/AIDS [23]. Nigeria has the highest number of AIDS orphans in sub-Saharan Africa (an estimated 1.8 million in 2003). There is significant variation in HIV prevalence rates across the country with the hardest hit states being Benue and Cross River [47]. In 1987, after 6 years of watching people die, a new treatment emerged and was hailed as the first huge step in beating HIV/AIDS. The drug Retrovir (AZT, Zidovudine) was FDA approved and began to be used in high doses to treat people infected with HIV [24].

A decision to start treatment is based primarily on the CD4 count level and HIV viral load, and secondarily on the readiness of the patient to accept and adhere to lifelong treatment. In general, treatment is recommended for those patients with a CD4 count $<$ $350 / \mathrm{mm}^{3}$ [51]. Most HIV infected people require HIV treatment at some point during infection with the aid of antiretroviral therapy (ART). Antiretroviral drugs are a group of drugs that inhibit the reproduction of retroviruses-viruses composed of RNA rather than DNA [27].

Six different classes of antiretroviral agents (AVR) have been approved by the U.S FDA. They include: nucleoside reverse transcriptase inhibitors (NRTIs); non-nucleoside reverse transcriptase inhibitors (NNRTIs); Protease inhibitors (PIs); integrase inhibitors; fusion inhibitors (or entry inhibitors) and CCR5 receptor antagonists [6]. Several national and international expert panels have established numerous HIV treatment guidelines. Recommended regimens usually include three different ARV agents in combination, usually from two classes such as 1NNRTI + 2NRTIs or 1PI + 2NRTIs [31]. The Front Line Drug Regimen (FLDR) mostly used in the twenty-seven treatment sites across the country is Zidovudine + Lamivudine + Nevirapine (2NRTIs $+1 \mathrm{NNRTI}$ ) as a combined therapy, Efavirenz or Abacavir is used in place of Nevirapine. In some centers depending on the status - HIV Post Exposure Prophylaxis (PEP), Prevention of motherto-child-transmission (PMTCT), pregnancy or in children, this replacement is usually necessary [40].

Despite the efforts of various agencies and supports from international bodies in combating the spread as well as death from HIV/AIDS, patients on ART still continue to die as a result of side effects, particularly chronic toxicities [2, 35, 40]. The widespread use of protease inhibitors (PIs) and nucleoside and nucleotide inhibitors as antiretroviral drugs and their long-term administration has been associated with secondary metabolic adverse effects in some studies [7, 28]. Dyslipidemia, including hypertriglyceridemia or combined hyperlipidemia, as well as glucose intolerance and hyperinsulinism have been repeatedly reported $[1,3,9,32,41]$. In the meantime, the mechanisms that cause those metabolic alterations are not fully understood and are actively debated.

Nevertheless, these metabolic troubles are suspected to constitute risk factors for atherosclerosis as well as coronary artery disease (CAD) [7]. In most reports, the dyslipidemia with antiretroviral therapy has been assessed from measurements of lipids, cholesterol distribution, and of major apolipoproteins (Apos) [3, 32]. Increased levels of complex lipoparticles, containing Apoc111 and/or Apo E, and Apo B have been found in CAD patients [15].

Occurrence of lipodystrophy (LD) has also been commonly described on antiretroviral treatment, the most frequent aspect associating wastage of the face and limbs, and an increase in abdominal fat $[9,10,7,29]$. Despite the elevated prevalence of this $\mathrm{LD}$ (between $30 \%$ and $70 \%$ among studies), the factors or metabolic indices associated with its developments have not yet been clearly elucidated [7].

On the contrary, several studies have demonstrated that many factors may contribute to the pathogenesis of dyslipideamia, an increased synthesis of triglycerides (TGs) and very low - density lipoproteins (VLDLs), a lipolysis defect modulating both the synthesis and catabolism of VLDLs [4, 27]. Dyslipideamia as an established risk factor of cardiovascular diseases has therefore been reported in HIV/AIDS. However, the incidence of cardiovascular disease in HIV-infected patients receiving antiretroviral therapy is low. Although, the risk of cardiovascular disease is increased when compared with that in uninfected persons. This fact is substantially due to a higher prevalence of underlying traditional cardiovascular risk factors that are mostly host dependent and HIV contributing both directly through immune activation and inflammation, and indirectly through immunodeficiency [28].

Also, against the previous studies of antiretroviral treatment some authors $[2,19]$ argued that cardiovascular complications in the course of human immunodeficiency virus (HIV) infection are multifactorial and may be caused by the virus itself or by the related opportunistic infections and neoplasms and that the course of vascular disease may be accelerated in HIV infected patients because of atherogenesis stimulated by HIV-infected monocytemacrophages, possibly via leukocyte adhesion or arteritis.

In view of the conflicting reports aforementioned, this study is designed to investigate and distinguish the effect of HIV infection from its treatment on lipid profile in HIV-infected subjects. Meanwhile, with the use of potent ART in patients with HIV disease, so many researchers have noted changes in lipid parameters and glucose homeostasis [2, 32]. However, these effects have been difficult to interpret because of the varied demographic and treatment characteristics of the cohorts and the complexity of differentiating the effect of HIV disease from that of the drugs used in its treatment. This study is designed to explore the issues aforementioned by clarifying the actual cause of dyslipidemia between the HIV disease and its ART treatment.

\section{Materials and Method}

This study was conducted at Ladoke Akintola University of Technology Teaching Hospital, LAUTECH, Osogbo located in 
the core of southwestern, Nigeria.

\section{Subject Selection and Sample Size}

One hundred and twenty (120) participants were enrolled in this study. Consecutive HIV-positive patients attending the hospital both for follow-up consultation and the newly diagnosed patients between the ages of 18-55 years were randomly selected. To get reference control values for all investigated parameters, subjects of both sexes with age related and living in the same geographical area were also recruited. The study commenced after the proposal had been reviewed and approved by LAUTECH Ethical Committee with the assistance of the laboratory scientist incharge. The subjects were grouped as follows;

1. Fourty HIV-infected subjects on treatment for three months and above, $\{\mathrm{M}=20, \mathrm{~F}=20\}$.

2. Fourty newly diagnosed HIV infected subjects, treatmentnaive, $\{M=16, F=24\}$.

3. Fourty HIV-negative subjects, but living in the same geographical area, $\{\mathrm{M}=17, \mathrm{~F}=23\}$.

\section{Inclusion and exclusion criteria}

Subjects with the following manifestations were excluded based on their clinical history (and diagnosis); DM (Diabetes Mellitus), jaundice, hepatitis, hypothyroidism, hypertensions and nephrotic syndrome. Likewise, participants using contraceptives and corticosteroid therapy were equally excluded.

\section{Laboratory methods}

Ten milliliters $(10 \mathrm{mls})$ of venous blood was collected from the cubital vein of each subject using a sterile needle and syringe into an appropriate bottle (EDTA-bottle). The plasma extracted by centrifugation for 10 minutes at $4000 \mathrm{rpm}$ into plain bottle and stored at $-20^{\circ} \mathrm{C}$ until the time of analysis.

Lipid profile: The plasma concentrations of total cholesterol, triglyceride, high density lipoprotein, total cholesterol were measured using spectrophotometry method.

Plasma cholesterol was estimated by an enzymatic method [44]. Cholesterol was determined after an enzymatic hydrolysis and oxidation. The mixture was incubated at room temperature for ten minutes after which the absorbance was read at wavelength of $500 \mathrm{~nm}$. Plasma triglyceride was estimated using the enzymatic method of [8] Triglyceride was determined after enzymatic hydrolysis with lipases. The mixtures were mixed thoroughly and then incubated for 10 minutes at room temperature. The absorbance was then read at wavelength of $500 \mathrm{~nm}$.

HDL-Cholesterol was estimated using a precipitated method [5]. In the presence of phosphotungstic acid and magnesium chloride, LDL, VLDL and chylomicrons were precipitated on centrifugation for 10 minutes at $4000 \mathrm{rpm}$.

The supernatant was separated immediately and the cholesterol content was determined. Centrifugation left with only the HDL in the supernatant; HDL-c fraction freed as supernatant was taken as sample containing HDL fraction which was successively determined using cholesterol assay method.
Calculation: After the estimation of total cholesterol, TG and HDL-C as stated above, LDL-C was calculated using Friedewald formula stated as follows; LDL-C = Total cholesterol-(TG $/ 5+$ HDL).

This was applicable since the concentration of cholesterol and TG was less than $400 \mathrm{mg} / \mathrm{dl}$ [16]. Similarly, TC/HDL-C and LDL-C/HDL-C ratios were also calculated.

CD4+ cell count: CD 4 T-cells were counted using a method of flow cytomery. Analysis with the aid of Partec flow cytometer by TUV Rheinland.

Flow cytometry was a useful method by which cell or micro particles in suspension were differentiated and counted according to cell size, fluorescence emission and internal structure [19].

\section{Statistical Analysis}

Results were reported as means ( $\pm \mathrm{SE}$ ) with analysis of variance (ANOVA). Means were also analyzed using Post Hoc test to compare the significant variables. Pearson's correlation coefficient (r) was used to determine the relationship between means of the variables. Results were regarded as significant at $\mathrm{P}<0.05$.

\section{Results and Interpretation}

Table 1 shows analysis of variance (ANOVA) of the means $( \pm$ SEM) of lipid, lipoparticle levels, CD4 cell count and age for $\mathrm{HIV}+$ on ART treatment (group 1), HIV + treatment naïve (group 2 ) and the controls (group 3). The mean total cholesterol value $(\mathrm{mmol} / \mathrm{L})$ in people with HIV+ on treatment $(3.69 \pm 0.07)$ was significantly lowered $(\mathrm{p}<0.05)$ compared with the controls $(5.32$ $\pm 0.09)$. Whereas, there was a significant increase in this mean value of $\mathrm{HIV}+$ on treatment $(3.69+0.07)$ when compared with treatment naive $(2.43 \pm 0.04)$. On the contrary, the triglyceride mean values $(\mathrm{mmol} / \mathrm{L})$ in people with $\mathrm{HIV}+$ on treatment $(1.87$ $\pm 0.03)$ and $\mathrm{HIV}+$ patients treatment naïve $(1.97 \pm 0.02)$ were both significantly increased $(\mathrm{p}<0.05)$ compared with the controls $(1.18 \pm 0.05)$. But the mean triglyceride value of $\mathrm{HIV}+$ treatment naïve $(1.97 \pm 0.02)$ was significantly higher than that of mean value of $\mathrm{HIV}+$ on treatment $(1.87 \pm 0.03)$.

However, the mean values of HDL-C $(\mathrm{mmol} / \mathrm{L})$ in people with $\mathrm{HIV}+$ on treatment $(0.99 \pm 0.04)$ and $\mathrm{HIV}+$ patients treatment naïve $(0.85 \pm 0.02)$ were significantly lowered $(\mathrm{p}<0.05)$ compared with controls $(1.43 \pm 0.04)$. Nevertheless, the mean value of HDL-C $(\mathrm{mmol} / \mathrm{L})$ in people with HIV+ on treatment $(0.99 \pm$ 0.04) was significantly higher compared with $\mathrm{HIV}+$ treatment naive $(0.85 \pm 0.02)$. LDL-C mean values $(\mathrm{mmol} / \mathrm{L})$ in people with $\mathrm{HIV}+$ on treatment $(2.12 \pm 0.08)$ and HIV + patients treatment naïve $(0.60 \pm 0.03)$ were significantly lowered $(p<0.05)$ when compared with controls $(3.32 \pm 0.09)$. But there was a significant increase in mean value of HIV+ on treatment $(2.12 \pm 0.08)$ when compared with treatment naïve $(0.60 \pm 0.03)$.

Different from some patterns above, TC/HDL-C mean value for the people with HIV + on treatment $(4.40 \pm 0.27)$ was significantly increased $(p<0.05)$ than both treatment naïve $(2.99 \pm 0.09)$ and controls $(3.77 \pm 0.09)$. Also, LDL/HDL-C mean value for the 
Table 1. Mean \pm SEM of lipids, lipoparticle levels, CD4 cell count and age for HIV+ patients on treatment, treatment naïve and controls using ANOVA and Post Hoc tests.

\begin{tabular}{|c|c|c|c|c|c|}
\hline PARAMETERS & $\begin{array}{c}\text { GROUP 1 } \\
\mathbf{N}=\mathbf{4 0}\end{array}$ & $\begin{array}{c}\text { GROUP 2 } \\
\mathbf{N = 4 0}\end{array}$ & $\begin{array}{c}\text { GROUP 3 } \\
\mathbf{N = 4 0}\end{array}$ & F-VALUE & P-VALUE \\
\hline $\begin{array}{c}\text { Total cholesterol } \\
(\mathrm{mmol} / \mathrm{l})\end{array}$ & $3.69 \pm 0.07^{\mathrm{a}, \mathrm{b}}$ & $2.43 \pm 0.04^{\mathrm{a}}$ & $5.32 \pm 0.09$ & 469.991 & $0.001^{*}$ \\
\hline $\begin{array}{c}\text { Triglycerides } \\
(\mathrm{mmol} / \mathrm{l})\end{array}$ & $1.87 \pm 0.03^{\mathrm{a}, \mathrm{b}}$ & $1.97 \pm 0.02^{\mathrm{a}}$ & $1.18 \pm 0.05$ & 143.924 & $0.001^{*}$ \\
\hline $\begin{array}{c}\text { HDL-cholesterol } \\
(\mathrm{mmol} / \mathrm{l})\end{array}$ & $0.99 \pm 0.04^{\mathrm{a}, \mathrm{b}}$ & $0.85 \pm 0.02^{\mathrm{a}}$ & $1.43 \pm 0.04$ & 79.678 & $0.001^{*}$ \\
\hline $\begin{array}{c}\text { LDL-cholesterol } \\
\text { (mmol/l) }\end{array}$ & $2.12 \pm 0.08^{\mathrm{a}, \mathrm{b}}$ & $0.60 \pm 0.03^{\mathrm{a}}$ & $3.32 \pm 0.09$ & 406.316 & $0.001^{*}$ \\
\hline TC/HDL-c & $4.40 \pm 0.27^{\mathrm{a}, \mathrm{b}}$ & $2.90 \pm 0.09^{\mathrm{a}}$ & $3.77 \pm 0.09$ & 18.628 & $0.001^{*}$ \\
\hline LDL/HDL-c & $2.44 \pm 0.21^{\mathrm{b}}$ & $0.73 \pm 0.05^{\mathrm{a}}$ & $2.39 \pm 0.09$ & 53.559 & $0.001^{*}$ \\
\hline CD4 (cells/ $/ \mathrm{ll})$ & $468.83 \pm 19.48^{\mathrm{a}, \mathrm{b}}$ & $183.55 \pm 21.79^{\mathrm{a}}$ & $886.60 \pm 12.62$ & 344.143 & $0.001^{*}$ \\
\hline Age $(\mathrm{yrs})$ & $33.73 \pm 1.26$ & $37.23 \pm 1.39$ & $34.10 \pm 1.35$ & 2.075 & 0.130 \\
\hline
\end{tabular}

KEY: Group 1- HIV positive patients on ART treatment; TC-Total cholesterol.

Group 2 - HIV positive patients (treatment naïve); CD4 - Cluster of differentiation

Group 3 - HIV negative patients (controls); HDL - High density lipoprotein; LDL - Low density lipoprotein; *= statistically significant ( $\mathrm{p} \leq$ 0.05); $\mathrm{a}=$ significantly different from controls (Post Hoc); $\mathrm{b}=$ significantly different from treatment naïve (Post Hoc).

people with $\mathrm{HIV}+$ on treatment $(2.44 \pm 0.21)$ was significantly higher $(\mathrm{p}<0.05)$ than both groups of treatment naïve $(0.73 \pm$ $0.05)$ and controls $(2.39 \pm 0.09)$. In addition, the CD4 cell count mean value of the people with $\mathrm{HIV}+$ on treatment $(468.83 \pm$ 19.48) was significantly higher $(\mathrm{p}<0.05)$ than for HIV+ group of treatment naïve $(183.55 \pm 21.79)$ but significantly less than the controls $(886.60 \pm 12.62)$. No significant value $(\mathrm{p}<0.05)$ was recorded comparing the mean value of age (years) in HIV+ patients on treatment $(33.73 \pm 1.26)$ with treatment naïve $(37.23$ $\pm 1.39)$ and the controls $(34.10 \pm 1.35)$.

Table 2 shows correlation of parameters within a group of patients with $\mathrm{HIV}+$ on treatment, significant positive correlations were observed within the group pairs of analytes as follows; TC and LDL-c $(\mathrm{r}=0.844, \mathrm{P}<0.01)$, TC and LDL/HDL-c ratio $(\mathrm{r}=$ 0.359, $\mathrm{p}<0.05)$, TG and TC/HDL-c ratio $(\mathrm{r}=0.358, \mathrm{p}<0.05)$, HDL-c and LDL-c $(\mathrm{r}=0.472, \mathrm{p}<0.01)$, HDL-c and TC/HDL-c $(\mathrm{r}=0.865, \mathrm{p}<0.01)$, HDL-c and LDL/HDL-c $(\mathrm{r}=0.853, \mathrm{P}$ $<0.01)$, LDL-c and TC/HDL-c $(\mathrm{r}=0.634, \mathrm{p}<0.01)$, LDL-c and LDL/HDL-c $(\mathrm{r}=0.710, \mathrm{p}<0.01), \mathrm{LDL}$ and CD4+ count $(\mathrm{r}=0.344, \mathrm{p}<0.01)$, and TC/HDL-c and LDL/HDL-c ratios $(\mathrm{r}=0.993, \mathrm{p}<0.01)$ respectively. While a significant negative correlation was observed in TG and CD4+ cell count $(r=-0.507$, $\mathrm{p}<0.01)$ level.

Table 3 shows correlation of parameters within a group of patients with HIV+ treatment naïve, significant positive correlations were observed within the group pairs of analytes as follows; LDL-c and TC/HDL-c $(\mathrm{r}=0.771, \mathrm{p}<0.01)$, LDL-c and LDL/HDL-c $(\mathrm{r}$ $=0.915, \mathrm{p}<0.01)$, as well as TC/HDL-c and LDL/HDL-c ratios $(\mathrm{r}=0.780, \mathrm{p}<0.01)$ respectively. However, significant negative correlations were observed in TG and CD4+ cell count $(\mathrm{r}=$ -0.380, $\mathrm{p}<0.05)$ level, HDL-c and LDL-c $(\mathrm{r}=-0.730, \mathrm{p}<0.01)$, HDL-c and TC/HDL-c ratio $(\mathrm{r}=-0.703, \mathrm{p}<0.01)$ as well as HDL-c and LDL/HDL-c ratio $(r=-0.787, \mathrm{p}<0.01)$ respectively.
Table 4 shows correlation of parameters within a group of apparently healthy controls. Significant positive correlations were observed within the group as follows; TC and HDL-c ( $\mathrm{r}=0.484$, $\mathrm{p}<0.01)$, TC and LDL-c $(\mathrm{r}=0.742, \mathrm{p}<0.01), \mathrm{LDL}$ and TC/ HDL-c ratio $(\mathrm{r}=0.676, \mathrm{p}<0.01)$, LDL-c and LDL/HDL-c ratio $(\mathrm{r}=0.746, \mathrm{p}<0.01), \mathrm{TC} / \mathrm{HDL}-\mathrm{c}$ and LDL/HDL-c $(\mathrm{r}=0.984, \mathrm{p}$ $<0.01)$ ratios. While negative associations were observed between TG and LDL-c $(\mathrm{r}=-0.421, \mathrm{p}<0.01)$, TG and LDL/HDL-c ratio $(\mathrm{r}=-0.454, \mathrm{p}<0.01)$, HDL-c and TC/HDL-c $(\mathrm{r}=-0.733, \mathrm{p}<$ $0.01)$ as well as HDL-c and LDL/HDL-c $(r=-0.682, p<0.01)$ respectively.

Figure 1 shows effects of HIV infection on body lipid and lipoprotein levels and their typical changes following commencement of ART treatments. HIV infection revealed rise in TG and reductions in other lipoparticles. However, in the case of ART treatments, there was an improved HDL-c level but with associated increases in TC, TC/HDL-c, LDL/HDL-c and LDL-c levels.

\section{Discussion}

In this present study, a significant increase in triglyceride level and significant lowered values in total cholesterol, HDL-C, LDL-C, TC/HDL-C and LDL-C/HDL-C ratios with CD4 cell counts were observed in HIV infected subjects (not yet on treatment) compared with HIV-negative subjects.

This agrees with the findings of [33] which states that patients in HIV infection were reported to have hypocholesterolaemia with and sometimes without hypertriglyceridaemia. Also, [39] reported similar findings with this study in which there were significantly low levels of total cholesterol, HDL and LDL in HIV infected patients, and about $40 \%$ of HIV-infected subjects were reported to be hypocholesterolemic when compared to seronegative controls. This low level of total cholesterol, HDL and LDL, was described 
Table 2. Pearson's correlation coefficients of biochemical parameters in a group of patients with HIV-positive on treatment.

\begin{tabular}{|c|c|c|c|c|c|c|c|}
\hline Parameters & $\begin{array}{c}\text { TC } \\
(\mathrm{mmol} / \mathrm{l})\end{array}$ & $\begin{array}{c}\text { Triglyceride } \\
(\mathrm{mmol} / \mathrm{l})\end{array}$ & $\begin{array}{c}\text { HDL-c } \\
(\mathrm{mmol} / \mathrm{l})\end{array}$ & $\begin{array}{c}\text { LDL-c } \\
(\mathrm{mmol} / \mathrm{l})\end{array}$ & $\begin{array}{c}\text { TC } \\
\text { HDL-c }\end{array}$ & $\begin{array}{c}\text { LDL } \\
\text { HDL-c }\end{array}$ & $\begin{array}{c}\text { CD4 } \\
(\text { cells } / \mu \mathrm{l})\end{array}$ \\
\hline $\mathrm{TC}(\mathrm{mmol} / \mathrm{l})$ & 1 & -0.005 & 0.032 & $0.844^{* *}$ & 0.284 & $0.359 *$ & 0.300 \\
\hline Triglycerides $(\mathrm{mmol} / \mathrm{l})$ & & 1 & -0.171 & -0.113 & $0.358^{*}$ & 0.274 & $-0.507 * *$ \\
\hline HDL-c $(\mathrm{mmol} / \mathrm{l})$ & & & 1 & $0.472 * *$ & $0.865^{* *}$ & $0.853^{* *}$ & 0.029 \\
\hline LDL-c (mmol/l) & & & & 1 & $0.634^{* *}$ & $0.710^{* *}$ & $0.344 * *$ \\
\hline TC/HDL-c & & & & & 1 & $0.993 * *$ & 0.090 \\
\hline LDL/HDL-c & & & & & & 1 & 0.022 \\
\hline CD4 (cells $/ \mu \mathrm{l})$ & & & & & & & 1 \\
\hline
\end{tabular}

*Correlation significant at 0.05 level. ${ }^{* *}$ correlation significant at 0.01 level.

Table 3. Pearson's correlation coefficients of biochemical parameters in a group of HIV-positive treatment naïve.

\begin{tabular}{|c|c|c|c|c|c|c|c|}
\hline Parameters & $\begin{array}{c}\text { TC } \\
(\mathbf{m m o l} / \mathbf{l})\end{array}$ & $\begin{array}{c}\text { Triglyceride } \\
(\mathbf{m m o l} / \mathbf{l})\end{array}$ & $\begin{array}{c}\text { HDL-c } \\
(\mathbf{m m o l} / \mathbf{l})\end{array}$ & $\begin{array}{c}\text { LDL-c } \\
(\mathbf{m m o l} / \mathbf{l})\end{array}$ & $\begin{array}{c}\text { TC } \\
\text { HDL-c }\end{array}$ & $\begin{array}{c}\text { LDL } \\
\text { HDL-c }\end{array}$ & $\begin{array}{c}\text { CD4 } \\
(\mathbf{c e l l s} / \boldsymbol{\mu l})\end{array}$ \\
\hline TC $(\mathrm{mmol} / \mathrm{l})$ & 1 & 0.172 & -0.005 & 0.177 & 0.017 & 0.191 & -0.230 \\
\hline Triglycerides $(\mathrm{mmol} / \mathrm{l})$ & & 1 & 0.107 & -0.073 & -0.024 & -0.035 & $-0.380^{*}$ \\
\hline HDL-c(mmol/l) & & & 1 & $-0.730^{* *}$ & $-0.703^{* *}$ & $-0.787^{* *}$ & 0.251 \\
\hline LDL-c(mmol/l) & & & & 1 & $0.771^{* *}$ & $0.915^{* *}$ & -0.199 \\
\hline TC/HDL-c & & & & & 1 & $0.780^{* *}$ & -0.307 \\
\hline LDL/HDL-c & & & & & & 1 & -0.223 \\
\hline CD4 (cells/ $\mu \mathrm{l})$ & & & & & & & 1 \\
\hline
\end{tabular}

**correlation significant at 0.01 level, *Correlation significant at 0.05 level

Table 4. Pearson's correlation coefficients of biochemical parameters in apparently healthy controls.

\begin{tabular}{|c|c|c|c|c|c|c|c|}
\hline Parameters & $\begin{array}{c}\text { TC } \\
(\mathbf{m m o l} / \mathbf{l})\end{array}$ & $\begin{array}{c}\text { Triglycerides } \\
(\mathbf{m m o l} / \mathbf{l})\end{array}$ & $\begin{array}{c}\text { HDL-c } \\
(\mathbf{m m o l} / \mathbf{l})\end{array}$ & $\begin{array}{c}\text { LDL-c } \\
(\mathbf{m m o l} / \mathbf{l})\end{array}$ & $\begin{array}{c}\text { TC } \\
\text { HDL-C }\end{array}$ & $\begin{array}{c}\text { LDL } \\
\text { HDL-C }\end{array}$ & $\begin{array}{c}\text { CD4 } \\
(\mathbf{c e l l s} / \boldsymbol{\mu l})\end{array}$ \\
\hline TC $(\mathrm{mmol} / \mathrm{l})$ & 1 & 0.036 & $0.484^{* *}$ & $0.742^{* *}$ & 0.229 & 0.278 & 0.024 \\
\hline Triglycerides (mmol/l) & & 1 & 0.286 & $-0.421^{* *}$ & -0.308 & $-0.454^{* *}$ & -0.324 \\
\hline HDL-c (mmol/l) & & & 1 & -0.096 & $-0.733^{* *}$ & $-0.682^{* *}$ & 0.454 \\
\hline LDL-c (mmol/l) & & & & 1 & $0.676^{* *}$ & $0.746^{* *}$ & -0.215 \\
\hline TC/HDL-c & & & & & 1 & $0.984^{* *}$ & 0.372 \\
\hline LDL/HDL-c & & & & & & 1 & 0.272 \\
\hline CD4 (cells/ml) & & & & & & & 1 \\
\hline
\end{tabular}

** correlation significant at 0.01 level, ${ }^{*}$ Correlation significant at 0.05 level.

to be associated with elevated level of $\beta-2$ microglobulin. Low cholesterol levels are prevalent even during the early stages of $\mathrm{HIV}$ and associated with a specific alteration in immune function.

Consistent with earlier reports, this study also showed similar finding [22] with another study in which the decrease of CD4+ count due to disease progression was accompanied by a decrease in the total cholesterol, HDL-c, and LDL-c, and an increase in triglycerides. This hypertriglyceridemia, was also reported by other authors $[21,30]$ which may be correlated to opportunistic infections and to interferon- $\alpha$. The relationship between triglycerides (TG) and interferon-alpha (IFN- $\alpha$ ) in HIV-positive patients has been previously reported by [22].

In a further study by [20], IFN- $\alpha$ was found to increase TG by two main mechanisms: a decrease in TG clearance; and an increase of de novo hepatic lipogenesis and VLDL production. This hepatic lipogenesis was related with stimulation by three types of cytokines: tissue necrotic factor- alpha $(\mathrm{TNF}-\alpha)$, Interleukins 1 and 6 ( IL- 1 and IL-6) that increase hepatic levels of citrate; and IFN- $\alpha$ that does not increase hepatic citrate. Both decreased TG clearance and increased hepatic VLDL overproduction have been found in HIV-positive patients, and the hepatic increased lipogenesis correlates to IFN- $\alpha$ [20]. Again, by the level of immunological deficiency according to the CD4+ cell count, some authors $[38,37,13]$ determined the level of plasma triglycerides, total cholesterol and HDL-C in HIV infected individuals and came to the same conclusion with an increase in immunological deficiency and clinical development of HIV infection, lipid profile disorders-indicated by an increase in triglycerides level and decrease concentrations of HDL-C.

However, some authors $[12,13]$ reported contradictory findings that patients with AIDS had increased levels of LDL-c. Also in another report [14], higher total cholesterol was noted in subjects with associated AIDS-defining events, which contradicted these 
Figure 1. Bar Chart Showing Mean Distributions of Various Parameters in Patient and Control Groups.

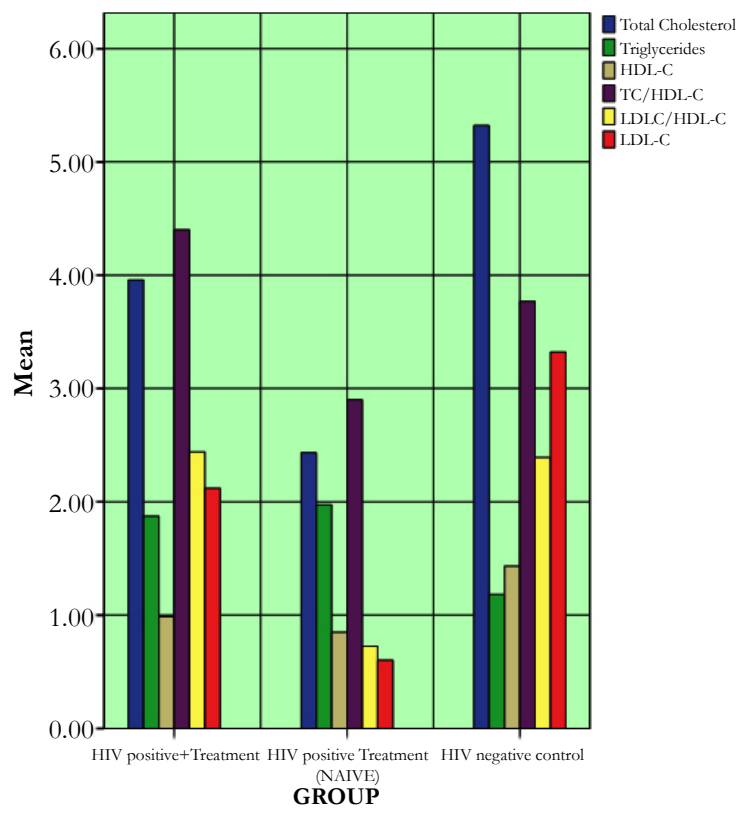

findings.

Furthermore, in this present study the effect of ART treatment on lipid profile as well as CD4+ cell count was drawn between the HIV-positive on ART treatment and HIV-positive not on treatment and a significantly reduced value in triglycerides with significant increases in total cholesterol, HDL-c, LDL-c, and TC/ HDL-c and LDL/HDL-c ratios with CD4 count were observed. This is corroborated by the result of [36] also supported by Gilead 903 studies, where it was stated that HAART subjects' median total cholesterol was significantly higher than the patients who were not on HAART, but was not different than those who were HIV uninfected. The same pattern was further noted in this study [36] for LDL cholesterol: women on HAART had been reported with higher levels than those who were HIV infected and not on treatment, but similar levels to uninfected women. Median high-density lipoprotein (HDL) cholesterol was higher in the HIV-uninfected women than in untreated HIV-infected women, although this was not significantly different from the median level of HAART recipients.

Certainly, other predominantly male studies, including [42, 49] and Gilead 903 studies, have demonstrated an increase in HDL cholesterol after NNRTI treatment therefore these results are congruent with what has been seen in men. This study, rather than identifying gender differences, supports a similar lipid response in men and women after HIV infection and HAART initiation and therefore agrees with our present study of combined gender in our participants. On the contrary, triglyceride levels were reported as highest in the HAART group; this was greater than among the HIV-uninfected women but not the untreated group, which partly contradicted our current finding.

It is crystal clear from the findings above that the concentrations of total cholesterol and LDL-c increase, following the initiation of treatment, surpassed the HDL-c level, and therefore call for assessment of possible risk factors of cardiovascular disease (CVD) in view of standpoints of TC/HDL-c as well as LDL-C/ HDL-c ratios. Also, according to [50], LDL-C is reported to have positive correlation with incidence of cardiovascular disease with nearly $75 \%$ of the plasma cholesterol incorporated into the LDL particles and possibly lead to myocardial infarction. From our present study, the ratios of both TC/HDL-c and LDL/HDL-c were found significantly increased. According to [43], an increase in TC/HDL-C is a pointer to coronary artery disease. Likewise, an increase in LDL-c is an atherogenic lipid marker while TC/ HDL-c and LDL/HDL-c ratios (atherogenic indices) have been attributed with more predictive power of cardiovascular risk [34]. Similarly, as TC/HDL-c is considered a more sensitive and specific index of cardiovascular risk than total cholesterol, this lipid ratio has been selected by the Canadian working group as a secondary goal of therapy [17].

\section{Conclusion}

With abnormal lipid profile findings in the present study, it shows that both HIV infection and ART treatment may cause metabolic alterations, however, the risk predictors, often termed atherogenic indices (TC/HDL-c and LDL/HDL-c ratios) were more noticeable in ART treatment and this may threaten a significant risk of developing cardiovascular disease.

\section{Reccomendations}

To further studies on the role of ART, differentiated from HIV infection, in the pathogenesis of metabolic syndrome and cardiovascular disease a multivariable analysis involving measurements of apo C-111, apo-E, liver enzymes, and heamatological parameters such as C-reactive protein and platelet count, probably involving multiracial or multinational dimension is needed. This is to further explore possible association of these biomarkers with liver function in apolipoprotein synthesis as well as inflammatory reactions.

However, researchers would continue to be at variance if individual ARV agents are not well studied rather than combination therapy, before their reports put side by side. 
Also and importantly, physicians should take note of possible toxicity associated with HAART especially for patients with underlying and predisposing factors before prescription and regimen are addressed.

\section{References}

[1]. Aalto-setala K, Fishet EA, Chen X (1992) Mechanism of hypertriglyceridemia in human apolipoprotein (Apo) C-111 transgenic mice. Diminished low density lipoprotein fractional catabolic rate associated with increased Apo C111 and reduced Apo E on the particles. J Clin Invest. 7(1): 221.

[2]. Barbaro G (2002) Increased access to the emergency department of coronary heart disease of HIV-infected patients receiving highly active antiretroviral therapy. Ann Emerg Med. 40(5): 530-531

[3]. Behrens G, Dejam A, Schmidt H, Balks HJ, Korner T, et al., (1999) Impaired glucose tolerance, B cell function and lipid metabolism in HIV patients under treatment with protease inhibitors. AIDS. 13(10): 63-70.

[4]. Beisiegel U, Weber W, Ihrke G, Herz J, Stanley KK (1989) The LDL-receptor-related protein, LRP, is an apoliprotein E-binding protein. Nature. 341(6238): 162-164

[5]. Benzie A (1979) An evaluation of a routine assay of serum High density lipoprotein cholesterol using dextran sulphate and magnesium chloride. Med lab Sci. 36(3): 289-291.

[6]. Birgit D, Mark H (2008) The relationship between HIV infection and cardiovascular disease. Curr Cardiol Rev. 4(3): 203-218.

[7]. Bonnet E, Ruidavets J, Tuech J, Ferrieres J, Collet X, et al., (2001) Apoprotein $\mathrm{C}-111$ and E-Containing liporpotarticles are markedly increased in HIV-infected patients treated with protease inhibitors: Association with the development of Lipodystrophy. J Clin Endocrinol Metab. 86(1): 296-302.

[8]. Buccolo G, David H (1973) Quantitative determination of serum triglyceride by the use of enzymes. Clin chem. 19(5): 476-482.

[9]. Carr A, Samara K, Burton S (1988) A syndrome of peripheral lipodystrophy, hyperlipidemia and insulin resistance in patients receiving HIV protease inhibitors. AIDS. 12(7): F51-F58.

[10]. Carr A, Samara K, Chisholm DJ, Cooper DA (1988) Pathogenesis of HIV-1 protease inhibitors-associated peripheral lipodystrophy, hyperlipidemia, and insulin resistance. Lancet. 351(9119): 1881-1883.

[11]. Cheesbrough M (2000) District Laboratory Practice in Tropical Countries. Volume 2, (2nd Edn), Cambridge University Press. 253.

[12]. Crook MA, Mir N (1999) Abnormal lipids and the acquired immunodeficient syndrome is there a problem and what should we do about it. Int J STD AIDS. 10(6): 353-356.

[13]. Ducobu J, Payen MC (2000) Lipids and AIDS. Rev Med Brux. 21(1): 1117.

[14]. El-Sadr WM, Lundgren JD, Neaton JD (2005) Cd4+ count-guided interruption of antiretroviral treatment. N Engl j Med. 355: 2283-96.

[15]. Ferrieres J, Perret B, Ruidavels JB, Taraszkiewicz D, Chap H, et al., (1999) The role of triglyceride-rich lipoproteins in predicting coronary artery disease. Eur Heart J. 22: 237.

[16]. Friedwald WT, Levy IR, Friedrickson DS (1972) Estimation of the concentration of low density lipoprotein cholesterol in plasma without use of the preparative ultracentrifugation. Clin chem. 18(6): 499-502.

[17]. Genest J, Frohlich J, Fodor G, McPherson R (2003) The work group on hypercholesterolemia and other dyslipidemias. Recommendations for the management of dyslipidemia and the prevention of cardiovascular diseases: summary of the 2003 update. CMAJ. 169(9): 921-924.

[18]. Gisselbrecht M (1999) Vasculitis during human acquired immunocourse of HIV disease, will reduce the incidence of deficiency virus infection. Pathol Biol. 47(3): 245-247.

[19]. Greeve B (2003) A new No-lyse, No-Wash Flow-Cytometric Method for the determination of CD4 T Cells in Blood Samples. Transfus Med Hemoth. 30(1): 8-13.

[20]. Grunfeld C, Feingold K (1992) Tumor necrosis factor, interleukin, and interferon induced changes in lipid metabolism as part of host defense. Proc Soc Exp Biol Med. 200(2): 224-227.

[21]. Grunfeld C, Kotler DP, Hamadeh R, Tierney A, Wang J, et al., (1989) Hypertriglyceridemia in the acquired immunodeficiency syndrome. Am J Med. 86(1): 27-31.

[22]. Grunfeld C, Kotler DP, Shigenaga JK, Doerrler W, Tierney A, et al., (1991) Circulating interferon-alpha levels and hypertriglyceridemia in the acquired immunodeficiency syndrome. Am J Med. 90(2): 154-162.

[23]. Henry J (2005) HIV/AIDS Policy Fact Sheet. Kaiser family foundation. 1-2.

[24]. Hoffmann C, Rockstroh JK, Kamps BS (2007) HIV Medicine. (15hㅐ Edn),
Flying Publishers, paris. ISBN: 3-924774-59-5.

[25]. Hui DY (2003) Effects of HIV protease inhibitor therapy on lipid metabolism. Prog lipid res. 42(2): 81-92.

[26]. Ileuma SA (2007) HIV/AIDS in Nigeria. Nat P Com 3.

[27]. Isaac A, Pillay D (2003) New drugs for treating resistant HIV-1: clinical management of virological failures remains an important and difficult issue for HIV physicians. Sex trans infe. 79(3): 176-183.

[28]. Martinez E, Larrousse M, Gatell JM (2009) Cardiovascular disease and HIV infection: host, virus, or drugs? Curr Opin Infect Dis. 22(1): 28-34.

[29]. Miller KD, Jones E, Yanovski JA, Shankar R, Feuerstein I, et al., (1988) Visceral abdominal-fat accumulation associate with use of indonavir. Lancet. 351(9106): 871-875.

[30]. Mildvan D, Machado SG, Wiletsk I, Grossberg SE (1992) Endogenous interferon and triglyceride concentrations to assess response to zidovudine in AIDS and advanced AIDS-related complex. Lancet. 339(8791): 453-456.

[31]. Panels on antiretroviral guidelines for adults and adolescents. Guidelines for the use of antiretroviral agents in HIV-1-infected adults and aldolescents. November, 2016.

[32]. Periard D, Telenti A, Sudre P, Theswiss C, Halfon P, et al., (1999) Atherogenic dyslipemia in HIV-infected individuals with protease inhibitors. The swiss HIV cohort study. Circulation. 100(7): 700-705.

[33]. Pasupathi P, Govindaswamy B, Ganesan S, Ayyaswamy D (2008) Changes in CD4 Cell Count, Lipid Profile and Liver Enzymes in HIV Infection and AIDS Patients. J Appl Biomed. 6(3): 139-145.

[34]. Pintó X, Ros E (2000) Lipidos sericos y prediccion del riesgo cardiovascular: importancia de los cocientes cholesterol total/cholesterol HDL y cholesterol LDL/cholesterol HDL. Clin Invest Arterioscl. 12(5): 267-287.

[35]. Rickerts V, Brodt H, Staszewski S, Stille W (2000) Incidence of myocardia infarctions in HIV-infected patients between 1983 and 1998: the Frankfurt HIV-cohort study. Eur J Med Res. 5(8): 329-333.

[36]. Riddler SA, Smit E, Cole SR (2003) Impact of HIV infection and HAART on serum lipids in men. JAMA. 289(22): 2978-2982.

[37]. Rigopoulos D, Gregoriou S, Paparizos V, Katsambas A (2007) AIDS in pregnancy, part II: Treatment in the era of highly active antiretroviral therapy and management of obstetric, anesthetic, and pediatric issues. Skin med. 6(2): 79-84.

[38]. Rogowska-Szadkowska D, Borzuchowska A (1991) The level of triglycerides, total cholesterol and HDL cholesterol in various stages of human immunodeficiency virus (HIV) infection. Pol Arch Med Wewn. 101(2): 145-150.

[39]. Shor-Posner G, Basit A, Lu Y, Cabrejos C, Chang J, et al., (1993) Hypocholesterolemia is associated with immune dysfunction in early human immunodeficiency virus-1 infection. Am J Med. 94(5): 515-520.

[40]. Smith DK, Grohskopf LA, Black RJ, Veronese F, Cheever L, et al., (2005) Antiretroviral postexposure prophylaxis after sexual, injection-drug use, or other nonoccupational exposure to HIV in the United States: recommendations from the U.S. Department of Health and Human Services. MMWR Recomm Rep. 54 (RR-2): 1-20.

[41]. Sullivan AK, Feher MD, Nelson MR, Gazzard BG (1998) Marked hypertriglyceridemia associated with ritonavir therapy (letter). AIDS. 12(11): 13931394

[42]. Tashima K (1999) Lack of clinical lipodystrophy in patients receiving efavirenz + NRTIs in study 006. The 39th Interscience Conference on Antimicrobial Agents and Chemotherapy, San Francisco. Calif. Abstract 1304.

[43]. Tietz WN (1986) Fundamental of Clinical Chemistry. 2nd Edition. Sounders \& Co. (Publishers) Philadephia, U.S.A.

[44]. Trinder P, Barham D (1972) Estimation of LDL-cholesterol in plasma. Clinical chem.78:19-22.

[45]. UNAIDS (2002) Report on the Global AIDS Epidemic.

[46]. UNAIDS (2002) Youth and HIV/AIDS: Opportunity in Crisis.

[47]. UNAIDS (2004). Report on the Global AIDS Epidemic.

[48]. U.S Department of Health and Human Services. Recommendation for use of antiretroviral drugs in pregnant HIV-1-infected women for maternal health and interventions to reduce perinatal HIV transmission in the United States. November, 2016

[49]. van Leth F, Phanuphak P, Gazzard B (2003) Lipid changes in a randomized comparative trial of first-line antiretroviral therapy with regimens containing either Nevirapine(NVP)) Alone, Efavirenz (EFP) Alone or both drugs combined, together with stavudine and Lamivudine (2NN Study). It is a part of the publication The 10th Conference on Retroviruses and Opportunistic Infections, The Body Pro.

[50]. Vasudevan DM, Sreekumari S (2007) Textbook of Biochemistry for Dental Students. (4th Edn), Jaypee Brothers Medical (publishers) New Delhi, India.

[51]. Veazey RS, Lackner A (2005) HIV swiftly guts the immune system. Nature Med. 11: 469-470. 